\title{
Mastite por leveduras em bovinos leiteiros do Sul do Estado de Minas Gerais, Brasil
}

\author{
Mastitis caused by yeasts in dairy herds in the South of the Minas Gerais State, Brazil
}

\author{
Geraldo Márcio da Costa ${ }^{\mathrm{I}^{*}}$ Nivaldo da Silva ${ }^{\mathrm{II}}$ Carlos Augusto Rosa ${ }^{\mathrm{III}}$ \\ Henrique César Pereira de Figueiredo ${ }^{I}$ Ulisses de Pádua Pereira ${ }^{\mathrm{I}}$
}

\section{RESUMO}

O objetivo deste trabalho foi estudar a freqüência de infecções intramamárias ocasionadas por leveduras a partir de amostras de leite $(n=1710)$ coletadas em 40 rebanhos leiteiros do Estado de Minas Gerais. Cinqüenta e seis estirpes de leveduras do gênero Candida e uma linhagem de Trichosporon loubieri foram isoladas. Candida albicans foi a espécie dominante (28,1\% das cepas), seguida por Candida parapsilosis (19,3\%), Candida catenulata (14,0\%), Candida glabrata (14,0\%) e Candida tropicalis (8,8\%). Infecções mistas foram detectadas em $29,8 \%$ das vacas levedura-positivas. Amostras positivas para leveduras foram predominantemente obtidas (84\%) de vacas com mastite subclínica. A baixa taxa de isolamento de leveduras sugere que estes microrganismos não são relevantes para mastite bovina na região estudada.

Palavras-chave: mastite bovina, mastite leveduras, Candida sp, Brasil.

\section{ABSTRACT}

The objective of this study was to report the frequency of intramammary infections by yeasts, in Minas Gerais State, from milk samples $(n=1710)$ collected in 40 dairy herds. Fifty six yeast strains of the genus Candida and one strain of Trichosporon loubieri were isolated. Candida albicans was the dominant species (28.1\% of the strains), followed by Candida parapsilosis (19.3\%), Candida catenulata (14.0\%), Candida glabrata (14.0\%), Candida tropicalis (8.8\%). Mixed infections were detected in $29.8 \%$ of yeast-positive cows. The yeast infection was more frequent (84\%) in cows with subclinical mastitis. The low rate of isolation of yeasts suggests that these microorganisms are not relevant to bovine mastitis in the studied region.

Key words: bovine mastitis, yeast mastitis, Candida sp, Brazil.

\section{INTRODUÇÃO}

A mastite bovina, sob o ponto de vista econômico, é a doença mais relevante de bovinos leiteiros em todos os continentes, afetando drasticamente a produção e a qualidade do leite e derivados (PYÕRÃLÃ, 2002). Diversos microrganismos, representados principalmente por bactérias, vírus, algas e fungos, estão envolvidos na mastite, tornando sua etiologia e epidemiologia complexas.

Entre os agentes considerados ambientais, leveduras têm sido relacionadas como patógenos emergentes em função das mudanças verificadas nos sistemas de produção de leite e nos programas de controle da mastite bovina, na última década. Diversas espécies dos gêneros Cryptococcus, Rhodotorula, Trichosporon e Candida têm sido isoladas de leite obtido de animais acometidos pela mastite, sendo as espécies do último geralmente as mais freqüentes (KRUKOWSKI et al., 2000; SANTOS \& MARIN, 2005).

Os dados disponíveis na literatura sobre a freqüência de infecções intramamárias (IIM) provocadas por leveduras apresentam grandes variações, encontrando-se índices variáveis entre 0,1\% e 17,3\%, sendo também muito variáveis as taxas de infecções mistas envolvendo estes agentes, em alguns casos com valores superiores a 50\% (FARNSWORTH \& SORENSEN, 1972; COSTA et al., 1993; AALBAEK et

IDepartamento de Medicina Veterinária, Universidade Federal de Lavras (UFLA), Lavras, MG, Brasil. E-mail: gmcosta@ufla.br. *Autor para correspondência.

IIEscola de Veterinária, Universidade Federal de Minas Gerais (EV/UFMG), Belo Horizonte, MG, Brasil.

IIIInstituto de Ciências Biológicas (ICB), UFMG, Belo Horizonte, MG, Brasil. 
al., 1994; MORETTI et al., 1998; WILSON et al., 1997; SANTOS \& MARIN, 2005).

Leveduras são microrganismos isolados facilmente a partir de equipamentos de ordenha, epitélio de tetos dos animais e do ambiente da sala de ordenha (KELLER et al., 2000; SANTOS \& MARIN, 2005). Altas taxas de isolamento destes microrganismos e elevados percentuais de amostras com crescimento misto sugerem falhas no momento de coleta de amostras destinadas a análises microbiológicas. Outro fato que pode justificar a presença do microrganismo no interior da glândula mamária são as falhas por ocasião da medicação de animais clinicamente acometidos, o que, ocasionalmente, tem sido relacionado como fator determinante de surtos de grandes proporções (MORETTI et al., 1998; CRAWSHAW et al., 2005).

O presente trabalho teve por objetivos estudar o envolvimento de leveduras na etiologia da mastite em rebanhos leiteiros da região Sul do Estado de Minas Gerais, identificando os gêneros e as espécies predominantes, a participação destes agentes nas formas clínica e subclínica da doença e a ocorrência de infecções mistas.

\section{MATERIAL E MÉTODOS}

Foram selecionados para o estudo 40 rebanhos leiteiros localizados na região Sul de Minas Gerais, pertencentes aos municípios de Boa Esperança, Bom Sucesso, Carrancas, Cordislândia, Cruzília, Ijací, Ingaí, Itumirim, Itutinga, Jesuânia, Lavras, Nazareno, Nepomuceno, Oliveira, Perdões, Ribeirão Vermelho, Santa Rita do Sapucaí, Santana da Vargem, Santo Antônio do Amparo e Três Corações. Foi estabelecido que os rebanhos utilizados no estudo deveriam empregar a ordenha mecânica e ter, pelo menos, 30 animais em lactação. Foi amostrado um número mínimo de 15 animais de cada uma das propriedades.

Nos estabelecimentos selecionados para o estudo, 2.560 vacas lactantes foram submetidas ao teste Tamis (prova da caneca de fundo escuro) e ao California Mastitis Test (CMT) visando o diagnóstico da mastite clínica e subclínica, segundo VEIGA (1998). Foram coletadas assepticamente 1.710 amostras de leite de 1.291 animais acometidos pela mastite, sendo 263 oriundas de casos clínicos e as demais de casos subclínicos.

As amostras foram coletadas imediatamente antes da ordenha. Os tetos amostrados foram previamente lavados com água corrente e submetidos à assepsia, empregando-se solução de iodo a 0,5\%, por 30 segundos. Estes foram enxugados com papel toalha, sendo que os três primeiros jatos foram descartados e foram coletados cerca de $10 \mathrm{~mL}$ de leite em tubos de ensaio esterilizados. Os espécimes foram acondicionados em caixa de isopor com gelo e prontamente remetidos ao laboratório.

Além da coleta de amostras de leite para a análise microbiológica, foram avaliadas as medidas gerais de prevenção e controle da mastite, incluindo higiene ambiental, higiene da ordenha, forma de tratamento dos casos clínicos e medicamentos utilizados. Os dados obtidos foram registrados em fichas individuais para cada rebanho e posteriormente correlacionados com os resultados microbiológicos.

As amostras de leite foram incubadas a $37^{\circ} \mathrm{C}$ por 8-12 horas. Depois foi realizada semeadura das mesmas em Sabouraud Dextrose Agar (Oxoid, USA), contendo 0,4g/L de cloranfenicol (Sigma, USA). Paralelamente, as amostras foram semeadas em ágar Sangue (Blood Agar Base-Oxoid, USA), contendo 10\% de sangue de carneiro para o isolamento de bactérias. Ambos os meios foram incubados a $37^{\circ} \mathrm{C}$ por $24-96$ horas, verificando-se a presença de crescimento microbiano diariamente.

As leveduras foram caracterizadas fenotipicamente segundo YARROW (1998), sendo a identificação realizada de acordo com chaves descritas por KURTZMAN \& FELL (1998). Microrganismos das famílias Staphylococcaceae e Streptococcaceae foram identificados de acordo com HOLT et al. (1994) e QUINN et al. (1994). Bactérias gram-negativas oxidase negativas foram identificadas utilizando-se os kits BACTRAY ${ }^{\circledR}$ I e II (Laborclin, Brasil), enquanto as oxidase-positivas foram identificadas utilizando-se o kit API 20NE (Biomerieux, França). Os demais agentes bacterianos foram identificados de acordo com QUINN et al. (1994). Amostras que apresentaram crescimento de três ou mais microrganismos diferentes nos meios utilizados para o cultivo foram descartadas, pois tal fato é indicativo de contaminação, segundo BRITO et al. (1999).

As freqüências de agentes isolados a partir de amostras obtidas de animais acometidos pela forma clínica ou subclínica da mastite e os índices de infecção mista envolvendo leveduras foram analisadas por meio do Teste do Qui-quadrado, empregando-se o Programa Epi-Info (CDC-WHO, version 6.04b,1997).

\section{RESULTADOS E DISCUSSÃO}

Entre as 1.710 amostras analisadas, 125 não apresentaram crescimento de microrganismos e 15 foram descartadas devido a indícios de contaminação (crescimento de mais que dois agentes diferentes). Leveduras apresentaram pouca expressão na etiologia 
da mastite, tendo sido isoladas de 57 amostras distribuídas entre 17 (42,5\%) entre os 40 rebanhos, sendo verificadas taxas de isolamento que variaram de zero a 25,5\%, comuma freqüência média de 3,4\%(Tabela 1).

A tabela 2 relaciona as espécies e a freqüência de leveduras isoladas. A maioria das leveduras isoladas (56), representando $98,2 \%$ das amostras, pertenceu ao gênero Candida. C. albicans, foi a espécie predominante, seguida por $\boldsymbol{C}$. parapsilosis, C. catenulata e C. glabrata, e $\boldsymbol{C}$. tropicalis. As demais espécies pertencentes ao gênero Candida representaram 15,8\% dos isolamentos. Os testes utilizados não permitiram a identificação da espécie de duas amostras de Candida spp.

Uma única amostra foi identificada como Trichosporon loubieri, perfazendo 1,8\% dos isolamentos, o que evidenciou a pouca relevância de microrganismos deste gênero na etiologia da mastite nos rebanhos estudados. Contudo, Trichosporon spp têm sido associado a IIM de bovinos, em alguns casos, predominando em relação às demais leveduras (MORETTI et al., 1998) e, em outros, determinando surtos de mastite clinica em bovinos leiteiros (GONZALEZ et al., 2001). Além do envolvimento na etiologia da mastite, a Trichosporon spp tem sido relacionado como um patógeno emergente,

Tabela 1 - Freqüências de infecções intramamárias ocasionadas por leveduras em rebanhos leiteiros do Sul de Minas Gerais, Brasil, no período de 2004 a 2006

\begin{tabular}{lccc}
\hline $\begin{array}{l}\text { Identificação } \\
\text { Rebanho }^{1}\end{array}$ & $\begin{array}{c}\text { Amostras } \\
\text { Analisadas }\end{array}$ & $\begin{array}{c}\text { Amostras } \\
\text { Positivas }\end{array}$ & $\begin{array}{c}\text { Amostras } \\
\text { Positivas (\%) }\end{array}$ \\
\hline 1 & 65 & 2 & 3,1 \\
2 & 45 & 1 & 2,2 \\
4 & 43 & 1 & 2,3 \\
6 & 19 & 1 & 5,6 \\
8 & 23 & 2 & 8,7 \\
9 & 35 & 4 & 12,1 \\
10 & 34 & 1 & 2,9 \\
11 & 82 & 4 & 4,9 \\
15 & 52 & 2 & 3,8 \\
16 & 61 & 2 & 3,3 \\
17 & 37 & 1 & 2,7 \\
18 & 24 & 1 & 4,2 \\
20 & 106 & 27 & 25,5 \\
22 & 39 & 1 & 3,6 \\
23 & 51 & 1 & 2,0 \\
28 & 45 & 4 & 8,9 \\
35 & 35 & 2 & 5,7 \\
Média & - & - & 3,4 \\
\hline
\end{tabular}

${ }^{1}$-Somente rebanhos positivos.

2-Média geral dos 40 rebanhos estudados. determinando quadros patológicos graves em pacientes imunossuprimidos (MARTY et al., 2003).

A freqüência média de isolamento de leveduras obtida no presente estudo $(3,4 \%)$ foi próxima daquelas relatadas por FARNSWORTH \& SORENSEN (1972) e KRUKOWSKI et al. (2006), com valores e 3,2 e $4,3 \%$, respectivamente. Contudo, a literatura registra grande variação nos índices de infecções intramamárias (IIM) ocasionados por leveduras, sendo citados valores que oscilam entre 0,1\% e 17,3\% (WILSON et al., 1997; SANTOS \& MARIN, 2005).

Quanto à predominância de Candida entre as leveduras isoladas e à grande diversidade de espécies identificadas, os resultados estão de acordo com os obtidos por SANTOS \& MARIN (2005) e KRUKOWSKI et al. (2006), demonstrando não haver o envolvimento seletivo de nenhuma espécie do gênero nas IIM de bovinos.

Os resultados se mostraram discrepantes daqueles obtidos por COSTA et al. (1993), que verificaram elevado índice de envolvimento de fungos $(25,4 \%)$ em IIM de bovinos procedentes de rebanhos do Estado de São Paulo, sendo Cryptococcus o gênero predominante. Também foram discrepantes em relação aos resultados obtidos por SANTOS \& MARIN (2005), que, em outro trabalho realizado neste mesmo Estado, verificaram uma taxa elevada de isolamentos de leveduras (10,0\%), embora Candida spp tenha sido o gênero predominante, representando $68,1 \%$ das amostras isoladas.

As diferenças observadas nas taxas de isolamento de leveduras e na participação dos diferentes agentes em relação à literatura podem estar relacionadas com a amostragem realizada, com o número de rebanhos trabalhados e com as diferentes condições da mastite neles vigentes e as estratégias empregadas para o controle da mesma, e com a forma de coleta das amostras para análise.

Verificou-se a ocorrência de associações de leveduras com outros patógenos em 29,8\% dos casos, sendo as associações com Corynebacterium bovis, Staphylococcus spp coagulase positivos (SCP), Staphylococcus spp coagulase negativos e Streptococcus agalactiae as mais freqüentes. Para os demais agentes isolados, a freqüência de infecções mistas $(10,7 \%)$ foi bastante inferior à frequência observada para leveduras, sendo as diferenças observadas estatisticamente representativas (Quiquadrado = 20,28 e $\mathrm{P}<0,01$ ). Elevados percentuais de infecções mistas envolvendo leveduras e bactérias foram também relatados por COSTA et al. (1993), MORETTI et al. (1998) e SANTOS \& MARIN (2005), com valores de 72,2\%, 52,7\% e 68,0\%, respectivamente. 
Tabela 2 - Freqüência de leveduras isoladas a partir de 1.710 amostras de leite procedentes de 40 rebanhos leiteiros do Sul de Minas Gerais, Brasil, no período de 2004 a 2006

\begin{tabular}{lcc}
\hline Espécie & $\begin{array}{c}\text { Freqüência } \\
\text { absoluta }\end{array}$ & Freqüência \% \\
\hline Candida albicans & 16 & 28,1 \\
Candida parapsilosis & 11 & 19,3 \\
Candida catenulata & 8 & 14,0 \\
Candida glabrata & 8 & 14,0 \\
Candida tropicalis & 5 & 8,8 \\
Candida rugosa & 2 & 3,5 \\
Candida krusei & 4 & 7,0 \\
Candida spp & 2 & 3,5 \\
Trichosporon loubieri & 1 & 1,8 \\
Total & 57 & 100,0 \\
\hline
\end{tabular}

Os resultados obtidos demonstraram que infecções mistas são comuns quando do envolvimento de leveduras nas IIM de bovinos. Segundo KELLER et al.(2000) e SANTOS \& MARIN (2005), leveduras são agentes comumente encontrados em locais úmidos e ricos em matéria orgânica, sendo inclusive isolados do exterior de tetos de animais sadios e de equipamentos de ordenha. Desse modo, altas taxas de isolamento destes agentes em cultura mista poderiam ser indicativas de contaminação das amostras no momento da colheita. Contudo, os índices de infecções mistas verificados foram bastante confiáveis, uma vez que foram criteriosamente observados os princípios de assepsia e de anti-sepsia por ocasião da coleta de amostras, o que pode ser constatado pelo pequeno número de amostras descartadas $(0,9 \%)$ por apresentarem contaminação.

Constatou-se neste estudo que animais submetidos à terapia intramamária excessiva e repetitiva para mastite eram aqueles que normalmente apresentam complicações clínicas caracterizadas pelo envolvimento de leveduras, fato este já relatado por COSTA et al. (1998) e MORETTI et al. (1998). Na maioria das propriedades estudadas, o tratamento de casos clínicos de mastite era feito geralmente de forma empírica, empregando-se vias e posologias inadequadas, sem o conhecimento dos agentes envolvidos e de seus perfis de sensibilidade, além de se delegar tal tarefa a indivíduos pouco qualificados que desconheciam os princípios básicos de assepsia e de anti-sepsia, necessários por ocasião da utilização de medicação intramamária. Tais fatos podem estar associados à introdução acidental de microrganismos na glândula mamária, justificando o elevado índice observado de infecções mistas (29,8\%).
Falhas na anti-sepsia e no tratamento intramamário repetitivo foram fatores desencadeantes de um surto de mastite em um dos rebanhos estudados (rebanho 20), no qual Candida spp foi isolada de 25,5\% das amostras de leite analisadas. Diferentemente de diversos surtos de mastite de etiologia micótica relatados na literatura (ELAD et al., 1995; CRAWSHAW et al., 2005), neste não se observou o predomínio de nenhuma espécie em particular, tendo sido isoladas C. albicans (33,3\%), C. catenulata (22,2\%), C. glabrata (18,5\%), C. parapsilosis $(11,1 \%)$, C. krusei (7,4\%), C. tropicalis (3,7\%) e Candida sp (3,7\%). Neste rebanho, a maioria dos animais a partir dos quais as culturas positivas foram obtidas compunha um lote que tinha histórico de mastite clínica e tratamento intramamário repetitivo recente.

Quanto à participação nos casos clínicos e subclínicos de mastite, verificou-se o envolvimento de leveduras predominantemente na forma subclínica da doença, com 84,2\% dos isolados obtidos de animais subclinicamente acometidos, valor muito próximo ao obtido para os demais patógenos isolados (85,5\%), com Qui-quadrado $\mathrm{X}^{2}=0,07$ e $\mathrm{P}=0,794$. Não se verificou a participação de nenhuma espécie em particular nos casos subclínicos. Os resultados foram semelhantes aos descritos por FARNSWORTH \& SORENSEN (1972), que relataram que leveduras do gênero Candida podem ser isoladas repetidas vezes de quartos com baixa CCS, existindo a tendência de as infecções serem subclínicas.

Apenas nove (15,8\%) entre os 57 isolados de leveduras foram obtidos de animais clinicamente acometidos. Não se observou o predomínio de nenhuma espécie em particular nestes casos, com exceção da espécie $\boldsymbol{C}$. tropicalis, para a qual três dos cinco isolados foram associados a casos clínicos. Contudo, o número de isolados desta espécie foi muito reduzido, inviabilizando análises fidedignas.

Um aspecto relevante nas mastites ocasionadas por leveduras é que existem poucos fármacos disponíveis no mercado para o tratamento destes tipos de infecção, questão agravada pelo fenômeno multiresistência (COUTINHO et al., 2007). Tal fato determina que a maioria destas infecções tenda à cronicidade, verificando-se a eliminação contínua do agente por longos períodos (ELAD et al., 1995), o que, muitas vezes, implica na esterilização dos quartos infectados ou no descarte dos animais acometidos.

\section{CONCLUSÕES}

Leveduras apresentaram pouca expressão na etiologia da mastite nos rebanhos estudados, com 
envolvimento predominantemente nos casos subclínicos. Candida foi o gênero predominante, verificando-se grande variação quanto às espécies envolvidas e quanto às taxas de infecções entre os diferentes rebanhos. Infecções mistas são comuns em mastites ocasionadas por leveduras.

\section{REFERÊNCIAS}

AALBAEK, B. et al. Mycotic and algal bovine mastitis in Denmark. APMIS, v.102, n.6, p.541-456, 1994.

BRITO, M.AV.P. et al. Padrão de infecção intramamária em rebanhos leiteiros: exame de todos os quartos mamários das vacas em lactação. Arquivo Brasileiro de Medicina Veterinária e Zootecnia, v.51, n.2, p.129-135, 1999.

COSTA, E.O. et al. Survey of bovine mycotic mastitis in dairy herds in the State of São Paulo, Brazil. Mycopathologia, v.124, n.1, p.13-17, 1993.

COSTA, E.O. et al. Infectious bovine mastitis caused by environmental organisms. Journal of Veterinary Medicine, Series B, v.45, p.65-71, 1998.

CRAWSHAW, W.M. et al. Outbreak of Candida rugosa mastitis in a dairy herd after intrammamary antibiotic treatment. Veterinary Record, v.156, n.25, p.812-813, 2005.

COUTINHO, L.C.A. et al. Perfil de sensibilidade e resistência de isolados de Candida spp em vacas de leite procedentes do Estado do Pernambuco. In: ENCONTRO DE PESQUISADORES EM MASTITES, 4., 2007, Botucatu/SP. Anais... Botucatu: Fundação de Medicina Veterinária e Zootecnia-Universidade Estadual de São Paulo, 2007. 118p. p.84.

ELAD, D. et al. Feed contamination with Candida krusei as a probable source of mycotic mastitis in dairy cows. Journal American Veterinary Medical Association, v.207, n.5, p.620-622, 1995.

EPI-INFO 6.04b-A word processing, database and statistics program for public health. Center of Disease Control \& Prevention (CDC). Geneva, Switzerland: World Health Organization, version 6.04b, 1997.

FARNSWORTH, R.J.; SORENSEN, D.K. Prevalence and species distribuition of yeasts in mammary glands of dairy cows in Minnesota. Canadian Journal Comparative Medicine, v.36, p.329-332, 1972.

GONZALEZ, R.N. et al. Outbreak of clinical mastitis caused by Trichosporon beigelii in dairy herds. Journal American
Veterinary Medical Association, v.218, n.2, p.238-42, 2001. HOLT, J.G. et al. Bergeys's manual of determinative bacteriology. 9.ed. Baltimore, USA: Williams \& Wilkins, 1994. 787p.

KELLER, B. et al. Differentiation of yeasts in mastitis milk. Mycoses, v.43, suppl.1, p.17-19, 2000.

KRUKOSWKI, H. et al. Survey of yeast mastitis in dairy herds of small-type farms in the Lublin region, Poland. Mycopathologia, v.150, p.5-7, 2000.

KRUKOSWKI, H. et al. Yeast and algae isolated from cows with mastitis in south eastern part of Poland. Poland Journal Veterinary Sciences, v.9, n.3, p.181-184, 2006.

KURTZMAN, C.P.; FELL, J.W. The yeasts, a taxonomic study. 4.ed. Amsterdam: Elsevier, 1998. 1055p.

MARTY, F.M. et al. Disseminated trichosporonosis caused by Trischosporon loubieri. Journal of Clinical Microbiology, v.41, n.11, p.5317-5320, 2003.

MORETTI, A. et al. Relationship between cell counts in bovine milk and the presence of mastitis pathogens (yeasts and bacteria). Journal of Veterinary Medicine, Series B, v.45, p.129-132, 1998.

PYÕRÃLÃ, S. New strategies to prevent mastitis. Reproduction in Domestic Animals, v.211, n.216, p.211216, 2002.

QUINN, P.J. et al. Clinical veterinary microbiology. London: Wolfe, 1994. 648p.

SANTOS, R.C.; MARIN, J.M. Isolation of Candida spp from mastitic bovine milk in Brazil. Mycopathologia, v.59, p.251253, 2005.

WILSON, D.J. et al. Bovine mastitis pathogens in New York and Pennsylvania: Prevalence and effects on somatic cell count and milk production. Journal of Dairy Sciences, v.80, p.2592-2598, 1997.

YARROW, D. Methods for the isolation and identification of yeasts. In: KURTZMAN, C.P.; FELL, J.W. The yeasts, a taxonomic study. Amsterdam: Elsevier, 1998. p.77-100.

VEIGA, V.M.O. Diagnóstico da mastite bovina. Juiz de Fora: EMBRAPA-CNPGL-ADT, 1998. 24p. (Circular Técnica, 51). 